九州大学学術情報リポジトリ

Kyushu University Institutional Repository

\title{
Numerical Analysis of Anaerobically Digested Slurry with Irrigation Water in Rice Paddy
}

Inomura, Ke isuke

Graduate School of Bioresource and Bioenvironmental Science

Yuge, Kozue

Department of Bioproduction Environmental Sciences, Faculty of Agriculture, Kyushu University

Anan, Mitsumasa

Takasaki Sogo Consultant Co. Ltd, .

Shinogi, Yoshiyuki

Department of Bioproduction Environmental Sciences, Faculty of Agriculture, Kyushu University

https://doi.org/10.5109/18689

出版情報: 九州大学大学院農学研究院紀要. 55 (2)，pp.357-363，2010-10. Faculty of Agriculture， Kyushu University

バージョン :

権利関係 : 


\title{
Numerical Analysis of Anaerobically Digested Slurry with Irrigation Water in Rice Paddy
}

\author{
Keisuke INOMURA ${ }^{1}$ Kozue YUGE,* Mitsumasa ANAN ${ }^{2}$ \\ and Yoshiyuki SHINOGI
}

\author{
Laboratory of Irrigation and Water Utilization, Division of Bioproduction Environmental Sciences, \\ Department of Agro-environmental Sciences, Faculty of Agriculture, \\ Kyushu University, Fukuoka 812-8581, Japan \\ (Received June 23, 2010 and accepted July 9, 2010)
}

\begin{abstract}
The objective of this study was to analyze the two-dimensional spatial and temporal distribution of anaerobically digested slurry in rice paddy fields. For this investigation, MIKE 21 HD (MI) was used, and advection and diffusion were taken into consideration. To verify the model for rice paddy fields, a field observation was conducted at a lysimeter, where anaerobically digested slurry was mixed with irrigation water and the fluctuations of $\mathrm{T}-\mathrm{N}$ at five points were measured. Though some factors, such as undulations on the soil surface, created discrepancies between anticipated and actual values, the overall calculations agreed with the measurements, indicating that the model was fairly adaptable. To estimate the uniformity of distribution of anaerobically digested slurry, the spatial and temporal distribution of T-N at the lysimeter was simulated with MI. The results indicated that T-N was not distributed evenly with low level T-N around the water inlet. To determine a method that would effectively distribute anaerobically digested slurry, a scenario with a trench and two inlets was simulated. Trenches $3.00 \times 10^{-2} \mathrm{~m}$ deep and $6.17 \times 10^{-2} \mathrm{~m}$ wide were installed longitudinally among the rice plants. In addition, both lateral and longitudinal inlets were introduced. The water from the inlet in the $x$-direction was faster than that in the $y$-direction. In this scenario, the blocks on the levee were removed, and T-N from both inlets was fixed in the entire simulation period. Also, T-N level was fixed the entire time, assuming that anaerobically digested slurry was continuously mixed with the irrigation water. The results revealed uniform distribution of anaerobically digested slurry in terms of $\mathrm{T}-\mathrm{N}$ in 50 minutes, indicating that those introductions effectively distributed anaerobically digested slurry in a rice paddy.
\end{abstract}

\section{INTRODUCTION}

The "Biomass Nippon" project used cattle manure as the main organic material in farmland (Nakamura et al., 2005). In this project, the use of biomass was promoted and the methane fermentation was emphasized because methane produces both biogas energy and manure (Ryu et al., 2009). Methane fermentation is the biomass conversion process to produce energy as methane and fertilizer as anaerobically digested slurry from feedstock biomass such as livestock waste and food residue (Nakamura et al., 2009). Livestock waste amounts to around $90,000,000$ t/year, which accounts for two percent of the entire industrial waste (Kawanishi et al., 2007). In Japan, organic waste from the livestock industry, for example, is fermented to produce methane, according to Nakano and Uehara (2005), but only a small amount of it is used for methane fermentation. To improve methane fermentation, the consumption of anaerobically digested slurry should be increased. The use of anaerobically digested slurry as fertilizer reduces maintenance costs at methane fermentation plants by decreasing the expense of treating anaerobically digested slurry (Iwata et al., 2009). According to Ministry of Agriculture, Forestry and

\footnotetext{
Laboratory of Irrigation and Water Utilization, Division of Regional Environment Science, Department of Bioproduction Environmental Science, Graduate School of Bioresource and Bioenvironmental Science

Takasaki Sogo Consultant Co., Ltd.

* Corresponding author (E-mail: yuge@bpes.kyushu-u.ac.jp)
}

Fisheries (2009), in Japan, paddy fields accounted for 54.4 percent of the total farm lands, indicating that the use of anaerobically digested slurry in paddy fields is critical to boost the consumption. Nakamura et al. (2005) studied the possibility of using anaerobically digested slurry as fertilizer in paddy fields by comparing the market of compost with that of digested slurry. Tanaka et al. (2009) investigated two different slurry irrigation systems and determined that anaerobically digested slurry is an effective fertilizer.

In paddy fields, anaerobically digested slurry is mixed with irrigation water to spread from inlets for follow-up fertilizer application. In this method, however, the growth of rice plants is often not uniform due to the uneven distribution of nutrients. According to Iwashita et al. (2008), there is a difference in the density of anaerobically digested slurry between areas near water inlets and those far from inlets. Nevertheless, research related to the distribution of the slurry has yet to be done.

The uneven distribution of anaerobically digested slurry can be caused by inefficient water flow; water inlets are not usually made to spread fertilizer, but to irrigate water. There may be areas where water is so stagnant that a sufficient amount of anaerobically digested slurry cannot be delivered. On the other hand, the lack of uniformity may be solved by changing the shape of inlets or water replacement at the inlets. Also, changing the topography of the soil surface can solve the problem. Iwashita et al. (2008) indicated that substantial water flow or trench digging may positively affect the distribution of 
digested slurry. To evaluate those ideas, simulation of water flow and advection and diffusion of anaerobically digested slurry is necessary.

This study analyzed the two dimensional spatial and temporal distribution of anaerobically digested slurry in paddy fields. For this analysis, MIKE 21 HD (MI) was used. MI is usually adapted to lakes, estuaries, bays, and seas, but may be applied wherever stratification can be neglected (DHI, 2008), such as in paddy fields. In this model, however, the viscosity is assumed to be uniform, even though anaerobically digestive slurry has a higher viscosity than water. Also, rice plants are assumed to be square blocks that do not allow water to pass through, making verification of the model necessary in a paddy field.

To verify the adaptability, a field observation was conducted at a lysimeter, where anaerobically digested slurry was mixed with irrigation water, and the fluctuation of T-N at each point was measured. Nitrogen was the important element to analyze because it is one of the three major nutrients and the major component of anaerobically digested slurry. After the model validation, the spatial and temporal distribution of $\mathrm{T}-\mathrm{N}$ at the lysimeter was simulated with MI. Furthermore, to invent an effective method to spread anaerobically digested slurry, a scenario with trenches and two inlets was simulated.

\section{METHODOLOGY}

\section{Model description}

In this study, to quantify advection and dispersion of anaerobically digested slurry in a rice paddy, MI was used. This is a general numerical modeling system for the simulation of water levels and flows by unsteady two-dimensional flows in one layer. In MI, the spatial and temporal variations of flow and water level are described by the following equations:

$$
\begin{aligned}
& \frac{\partial \zeta}{\partial t}+\frac{\partial p}{\partial x}+\frac{\partial q}{\partial y}=\frac{\partial d}{\partial t} \\
& \frac{\partial p}{\partial t}+\frac{\partial}{\partial x}\left(\frac{p^{2}}{h}\right)+\frac{\partial}{\partial y}\left(\frac{p q}{h}\right)+g h \frac{\partial \zeta}{\partial x}+\frac{g p \sqrt{p^{2}+q^{2}}}{C^{2} h^{2}} \\
& -\frac{1}{\rho_{w}}\left[\frac{\partial}{\partial x}\left(h \tau_{x x}\right)+\frac{\partial}{\partial y}\left(h \tau_{x y}\right)\right]+\frac{h}{\rho_{w}} \frac{\partial}{\partial x}\left(P_{a}\right)=0 \\
& \frac{\partial q}{\partial t}+\frac{\partial}{\partial y}\left(\frac{q^{2}}{h}\right)+\frac{\partial}{\partial x}\left(\frac{p q}{h}\right)+g h \frac{\partial \zeta}{\partial y}+\frac{g q \sqrt{p^{2}+q^{2}}}{C^{2} h^{2}} \\
& -\frac{1}{\rho_{w}}\left[\frac{\partial}{\partial y}\left(h \tau_{y y}\right)+\frac{\partial}{\partial x}\left(h \tau_{x y}\right)\right]+\frac{h}{\rho_{w}} \frac{\partial}{\partial y}\left(P_{a}\right)=0
\end{aligned}
$$

where $\zeta$ is the surface elevation (m), $t$ is the time (s), $p$ and $q$ are the flux densities in the $x, y$ directions $\left(\mathrm{m}^{2} / \mathrm{s}\right)$ $((p, q)=(u h, v h),(u, v)=$ depth averaged velocities in the $x, y$ directions $(\mathrm{m} / \mathrm{s})), d$ is the time varying water depth $(\mathrm{m}), h$ is the water depth $(\mathrm{m}), g$ is gravitational acceleration $\left(\mathrm{m} / \mathrm{s}^{2}\right), C$ is the Chezy resistance $\left(\mathrm{m}^{1 / 2} / \mathrm{s}\right)$ and given by $C=M h^{1 / 6}$ where $M$ is Manning resistance $\left(\mathrm{m}^{1 / 3} / \mathrm{s}\right), \quad \tau_{x x}, \tau_{x y}, \tau_{y y}$ are components of effective shear stress $\left(\mathrm{kg} / \mathrm{m} / \mathrm{s}^{2}\right), \rho_{w}$ is the density of water $\left(\mathrm{kg} / \mathrm{m}^{3}\right)$, and $p_{a}$ is the atmospheric pressure $\left(\mathrm{kg} / \mathrm{m} / \mathrm{s}^{2}\right)$. MI makes use of an Alternating Direction Implicit (ADI) technique to integrate the equations for mass and momentum conservation in the space-time domain. According to Sai et al. (2006), this technique has a better convergent quality compared with the explicit method.

The following advection-diffusion equation simulates the movement of anaerobically digested slurry:

$$
\frac{\partial c}{\partial t}+u \frac{\partial c}{\partial x}+v \frac{\partial c}{\partial y}=K_{x}+\frac{\partial^{2} c}{\partial x^{2}}+K_{y} \frac{\partial^{2} c}{\partial y^{2}}
$$

where $c$ is the compound concentration $(\mathrm{mg} / \mathrm{L})$ and $K_{x}$, $K_{y}$ are dispersion coefficients in the $x, y$ directions $\left(\mathrm{m}^{2} / \mathrm{s}\right)$. To solve this equation, the QUICKEST scheme is applied. It avoids the wiggle instability problem associated with central differencing of the advection terms and eliminates the numerical damping often experienced with first order upwinding methods (Ekebjaerg \& Justesen, 1991).

The extensive list of parameters used in the model is given in Table 1 . In this table, $h_{0}(\mathrm{~m})$ is the initial water depth and $Q\left(\mathrm{~m}^{3} / \mathrm{s}\right)$ is the water replacement rate at the inlet. $Q$ is given by $Q=v h x$.

Table 1. Parameters used by the numerical model, along with values

\begin{tabular}{cccc}
\hline Symbol & Parameter & Unit & $\begin{array}{c}\text { Value } \\
\text { considered }\end{array}$ \\
\hline$h_{0}$ & Initial water depth & $\mathrm{m}$ & $3.00 \times 10^{-2}$ \\
$M$ & Manning resistance & $\mathrm{m}^{1 / 3} / \mathrm{s}$ & $2.50 \times 10^{-2}$ \\
$K_{x}$ & Dispersion coefficients in the $x$-direction & $\mathrm{m}^{2} / \mathrm{s}$ & $2.30 \times 10^{-4}$ \\
$K_{y}$ & Dispersion coefficients in the $y$-direction & $\mathrm{m}^{2} / \mathrm{s}$ & $2.30 \times 10^{-4}$ \\
$\Delta t$ & Time step & $\mathrm{s}$ & $1.00 \times 10^{-1}$ \\
$Q$ & Water replacement rate at the inlet & $\mathrm{m}^{3} / \mathrm{s}$ & $2.56 \times 10^{-4}$ \\
$C_{0}$ & Compound concentration $(0 \leq t \leq 693)$ & $\mathrm{mg} / \mathrm{L}$ & $1.17 \times 10^{2}$ \\
$C_{1}$ & Compound concentration $(693<t)$ & $\mathrm{mg} / \mathrm{L}$ & 0 \\
\hline
\end{tabular}

\section{Field observation}

The validity of the numerical model for estimating spatial and temporal concentration of T-N was assessed with a lysimeter at Kyushu University. MI is generally applied to larger areas such as lakes, estuaries, bays, and seas. In this model, the viscosity was assumed to be uniformly similar to that of water; anaerobically digestive slurry has a comparably high viscosity. Also, square blocks were used to represent rice plants. Therefore, the adaptability of MI to paddy fields was necessary.

A schematic view of the lysimeter is shown in Fig. 1. The lysimeter was $5 \mathrm{~m} \times 5 \mathrm{~m}$ wide, where $20 \times 20$ rice plants were transplanted. The distance between each plant was $2.47 \times 10^{-1} \mathrm{~m}$.

Water from the inlet flowed at a constant rate of $2.56 \times 10^{-4} \mathrm{~m}^{3} / \mathrm{s}$, which is the possible fastest flow in the experimental field. Water was irrigated for 64 minutes 


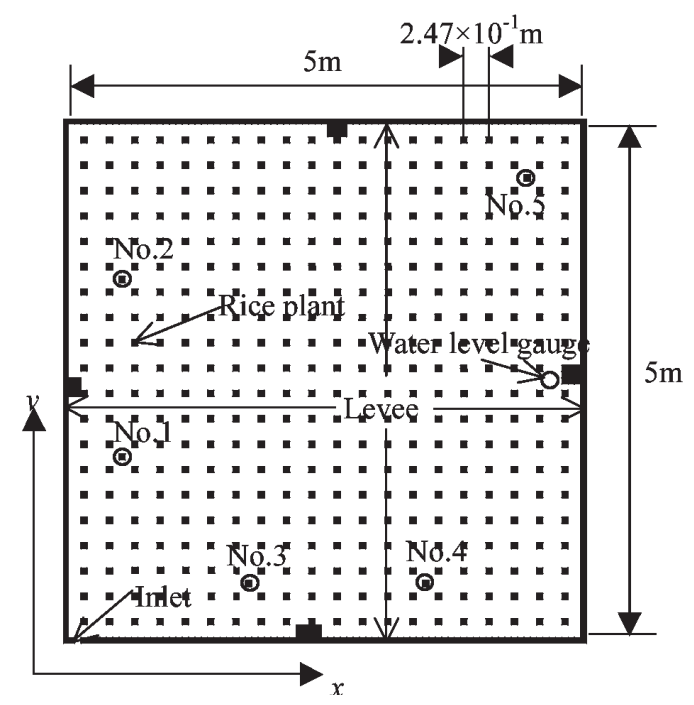

Fig. 1. Schematic view of the lysimeter used for field observation.

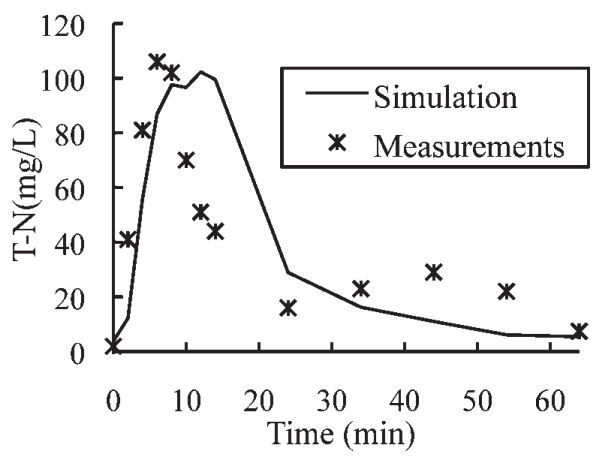

(a) No.1

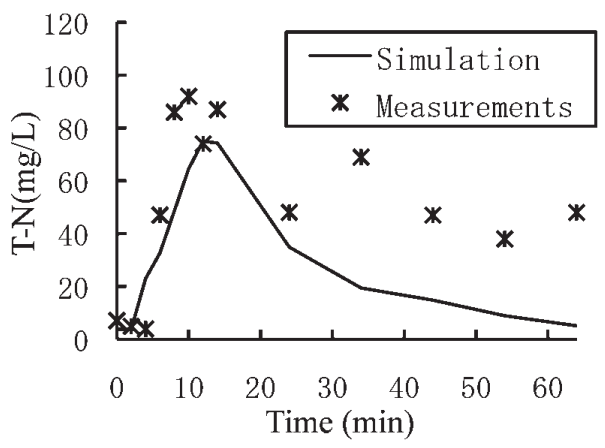

(c) No.3 because the peak of $\mathrm{T}-\mathrm{N}$ at each point was expected to appear within this time span. Fifteen L of anaerobically digested slurry was mixed with the water at a rate of $2.16 \times 10^{-5} \mathrm{~m}^{3} / \mathrm{s}$ from the beginning of the experiment. In $6.93 \times 10^{2}$ seconds, all the anaerobically digested slurry was provided. The initial water level at the water level gauge in Fig. 1 was $1.00 \times 10^{-2} \mathrm{~m}$; however, the soil surface was rugged and water level varied depending on the location. Thus, the initial water level in the simulation did not match the measured one. At points No.1 to No.5 in Fig. 1, water was collected by water-sampling bottles to measure $\mathrm{T}-\mathrm{N}$ every two minutes from the beginning to 14 minutes and every 10 minutes thereafter. After that, $\mathrm{T}-\mathrm{N}$ for each sample was measured in the laboratory.

\section{RESULTS AND DISCUSSION}

\section{Model validation}

$\mathrm{T}-\mathrm{N}$ was simulated with the numerical model and

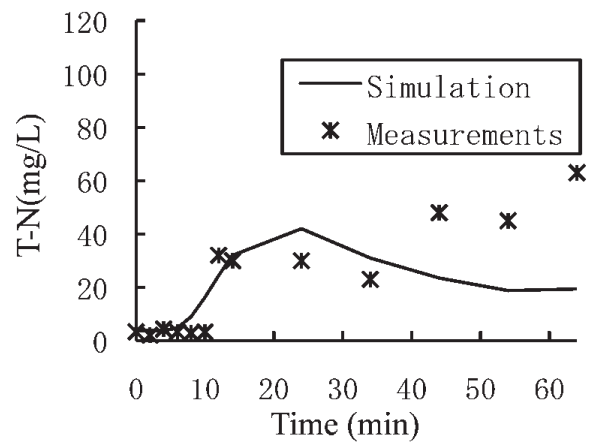

(b) No.2

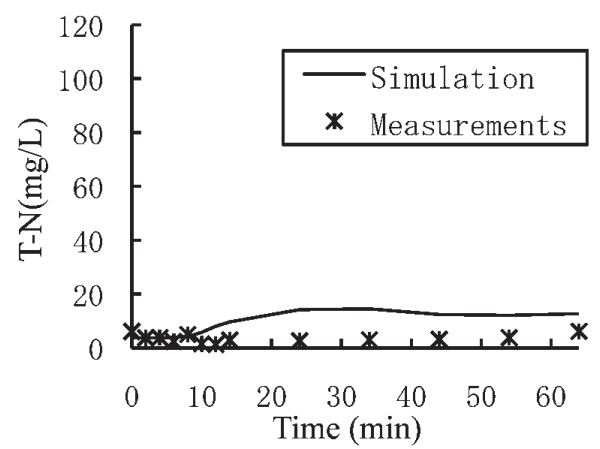

(d) No.4

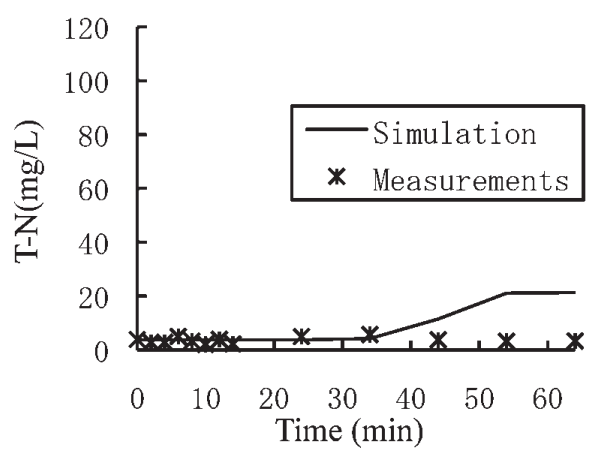

(e) No.5

Fig. 2. Comparison of the simulated and measured T-N at points No. 1 No. 5 . 
observed at each point of the lysimeter (Fig. 2). T-N increased first at No.1 because the water flowed longitudinally. Because water moved in the $y$-direction from the inlet, the water flow in that direction was advanced. This resulted in quick reach of $\mathrm{T}-\mathrm{N}$ at No. 1 , carried by the fast flow. No. 3 increased before the high concentration of T-N reached No. 2. Thus, the water flow was bent to the right by the levee block in the middle on the left and by the friction between water and the levee. Also, water flow was slowed by the friction between water and the soil surface, leading to the delay of T-N at No. 2. The graph of T-N at No. 4 and No. 5 in Fig. 2 shows only a slight increase in $\mathrm{T}-\mathrm{N}$, indicating that the anaerobically digestive slurry did not reach those points. According to this result, not enough anaerobically digested slurry was provided on the right side of the lysimeter. At No. 2 and No. 3, the distinction between the simulated and measured values was relatively large, especially in the latter half of the period. This was caused by the small varia- tions in the soil surface, which could not be taken into consideration in this model. The overall simulated result, however, reproduced the experimental data at each point, indicating the validity of the model.

\section{Adaptability of the Model for estimating the dis- tribution of anaerobically digested slurry}

The spatial and temporal distribution of $\mathrm{T}-\mathrm{N}$ in the lysimeter was simulated in the model. Figure 3 shows the distribution of T-N. The anaerobically digested slurry took 20 minutes to reach the center of the lysimeter. Also, even after 50 minutes, there were still some areas where $\mathrm{T}-\mathrm{N}$ did not increase. Thus, the method used to anaerobically spread digested slurry in the experiment was not uniform. Therefore, a more effective technique should be developed by considering the number of water inlets, amount of water in the mixture of anaerobically digested slurry, and introduction of trenches.

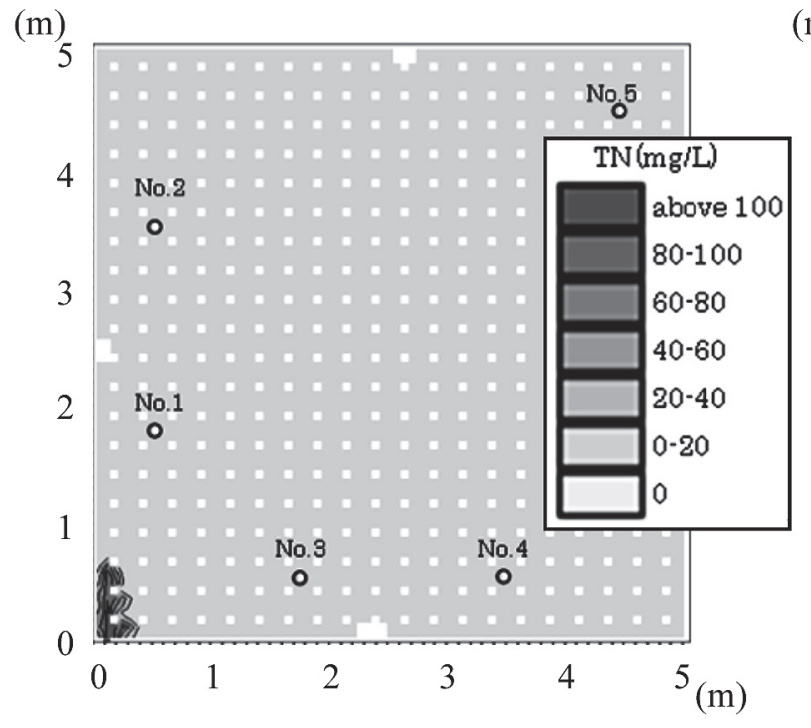

(a) Initial condition

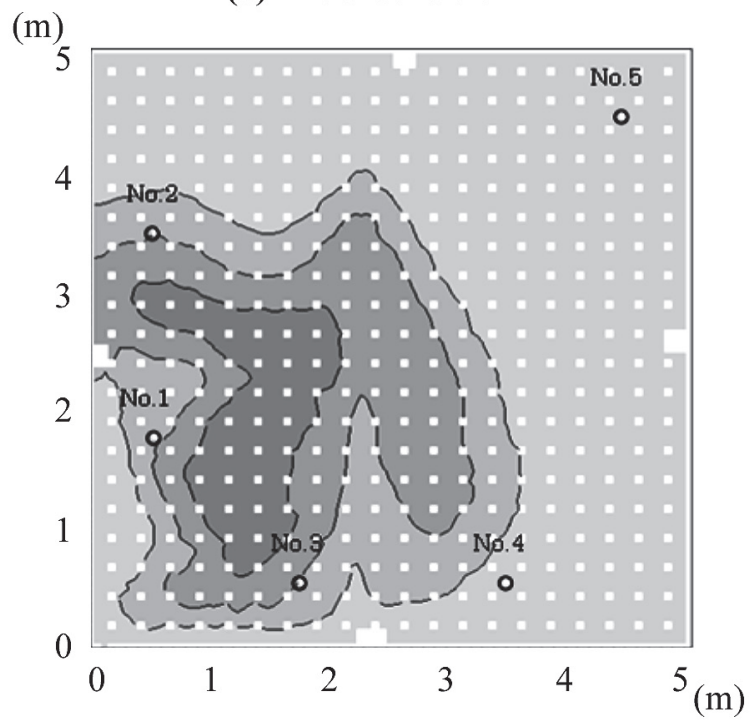

(c) 20 minutes later (m)

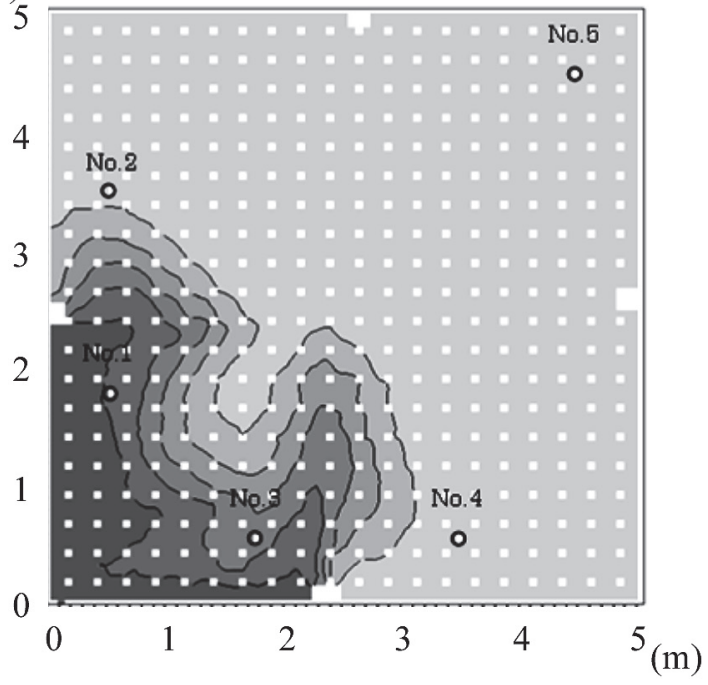

(b) 10 minutes later

(m)

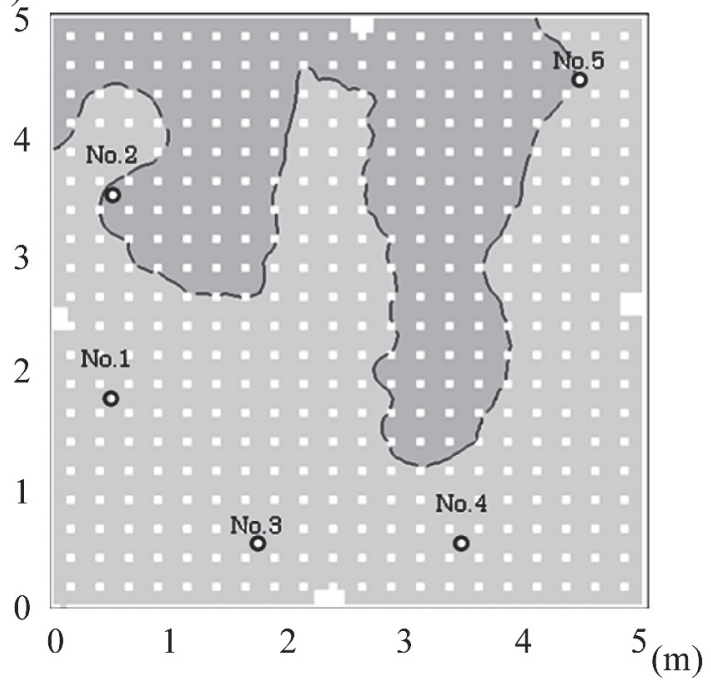

(d) 50 minutes later

Fig. 3. Change in the spatial distribution of $\mathrm{T}-\mathrm{N}$ in the simulation period. 


\section{Estimation of the distribution of anaerobically digested slurry in the lysimeter with trenches and double inlets}

To uniformly deliver anaerobically digested slurry, a scenario with introduction of trenches and two inlets was simulated. Trenches $3.00 \times 10^{-2} \mathrm{~m}$ deep and $6.17 \times$ $10^{-2} \mathrm{~m}$ wide were made longitudinally between the rice plants (Fig. 4). When the trenches were created, they were more than $8.00 \times 10^{-2} \mathrm{~m}$ deep and $1.00 \times 10^{-1} \mathrm{~m}$ wide, but they shrank by the time anaerobically digested slurry was applied. Trenches were made in paddy fields in Japan to remove poisonous gas from soil, to increase bearing power of soil, and to enable soil to dry quickly. Also, the positive effect of transverse deep zone has been studied previously (Lightbody et al., 2008).

Both lateral and longitudinal inlets were introduced at the bottom left corner of the lysimeter. The water flow of the inlet in the $x$-direction was faster than the one in the $y$-direction. The extensive list of parameters used in this setting is given in Table 2 . In this list, $Q_{x}$ and $Q_{y}$ are the water replacement rate at the lateral and longitudinal water inlet $\left(\mathrm{m}^{3} / \mathrm{s}\right)$. The blocks on the each side of the levee were removed.

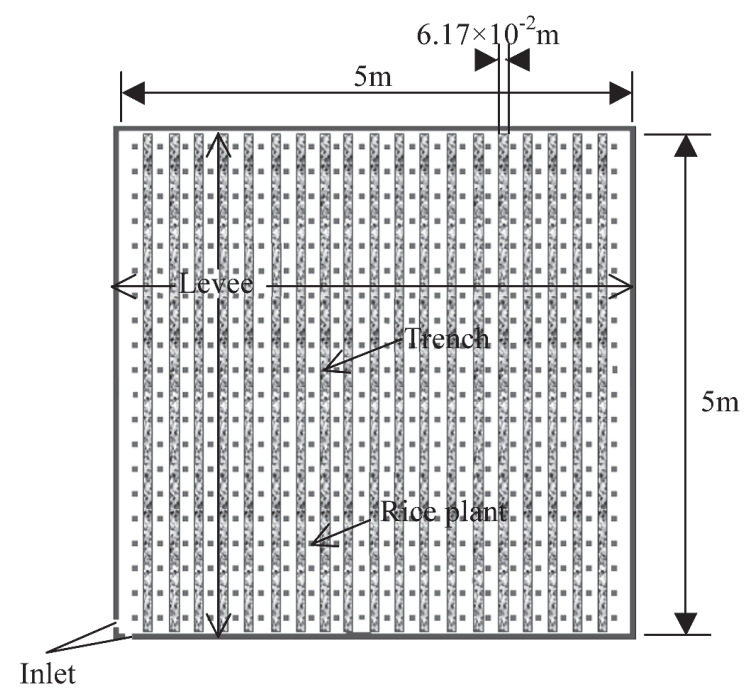

Fig. 4. Schematic view of the lysimeter with trenches and double inlets.

Table 2. Parameters used by the numerical model, along with values

\begin{tabular}{cccc}
\hline Symbol & Parameter & Unit & $\begin{array}{c}\text { Value } \\
\text { considered }\end{array}$ \\
\hline$h_{0}$ & Initial water depth & $\mathrm{m}$ & $3.00 \times 10^{-2}$ \\
$M$ & Manning resistance & $\mathrm{m}^{1 / 3} / \mathrm{s}$ & $2.50 \times 10^{-2}$ \\
$K_{x}$ & Dispersion coefficients in the $x$-direction & $\mathrm{m}^{2} / \mathrm{s}$ & $2.30 \times 10^{-4}$ \\
$K_{y}$ & Dispersion coefficients in the $y$-direction & $\mathrm{m}^{2} / \mathrm{s}$ & $2.30 \times 10^{-4}$ \\
$\Delta t$ & Time step & $\mathrm{s}$ & $1.00 \times 10^{-1}$ \\
$Q_{x}$ & Water replacement rate at the lateral & $\mathrm{m}^{3} / \mathrm{s}$ & $2.56 \times 10^{-4}$ \\
$Q_{y}$ & water inlet & $\mathrm{m}^{3} / \mathrm{s}$ & $4.57 \times 10^{-4}$ \\
$C_{0}$ & Compound concentration $(0 \leq t \leq 3600)$ & $\mathrm{mg} / \mathrm{L}$ & $4.20 \times 10$ \\
\hline
\end{tabular}

Figure 5 shows the distribution of $\mathrm{T}-\mathrm{N}$ at each period. $\mathrm{T}-\mathrm{N}$ was evenly distributed in 50 minutes, demonstrating the effectiveness of the scenario. The longitudinal water flow was accelerated by the trenches, which was likely the reason for the effective distribution of T-N.

\section{CONCLUSIONS}

To simulate the spatial and temporal T-N distribution of anaerobically digestive slurry in a rice paddy field, taking advection and diffusion into consideration, the two-dimensional hydrodynamic and transport model in MI was used. However, MI is generally applied to larger areas. Therefore, verification of the adaptability of MI to the lysimeter was necessary. To verify the application of MI, the field observation was conducted at the lysimeter, where water anaerobically digestive slurry was mixed with irrigation water, and the temporal distribution of $\mathrm{T}-\mathrm{N}$ at each point was measured. After verification, the spatial and temporal distribution of $\mathrm{T}-\mathrm{N}$ in the lysimeter was simulated with MI and the effective scenario for distributing anaerobically digested slurry was simulated. The results are as follows.

First, the model was verified by the field experiment. Although some factors, such as undulations on the soil surface, affected the reliability of calculated and measured numbers at some points, overall the results throughout the plot agreed with the measurements, proving the adaptability of the model.

Second, the spatial and temporal distribution of T-N in the lysimeter was not uniform according to the simulation in MI. In some areas, the $\mathrm{T}-\mathrm{N}$ level was low, and rice plants would not grow well. More effective techniques that consider the number of water inlets, the amount of water, mixed with anaerobically digested slurry, and introduction of trenches need to be developed.

Finally, in order to disperse anaerobically digested slurry, a new scenario was created. In this scenario, longitudinal trenches were made among the rice plants, and both lateral and longitudinal inlets were introduced at the bottom left corner of the lysimeter. The water flow in the $x$-direction inlet was faster than one in the $y$-direction inlet in this model, and the blocks on the levee were removed. Also, T-N level was fixed cor the entire time, assuming that anaerobically digested slurry was continuously mixed in the irrigation water. The results revealed the uniform distribution of $\mathrm{T}-\mathrm{N}$ in 50 minutes, indicating that those changes made in the new scenario led to the effective fertilization of anaerobically digested slurry.

\section{REFERENCES}

DHI 2008 MIKE 21 FLOW MODEL Hydrodynamic Module User Guide. DHI pp. 11

Ekebjaerg, L., \& P. Justesen, 1991 An explicit scheme for advection-diffusion modeling in two dimensions, Computer methods in Applied Mechanics and Engineering 88: 287297

Iwata, M., Iwashita, K., \& Fukushi, K. 2009 The manure component of digested slurry from methane fermentation in rural 
(m)

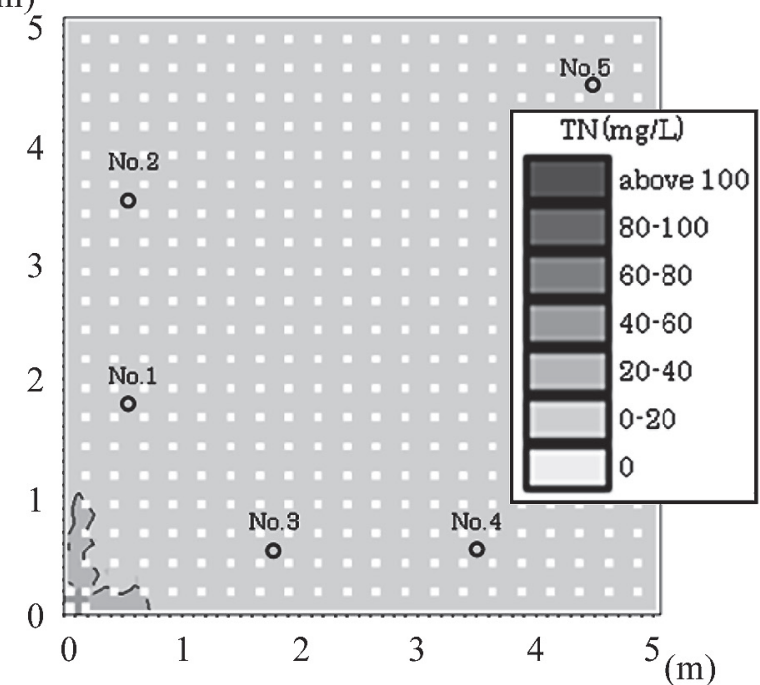

(a) Initial condition

(m)

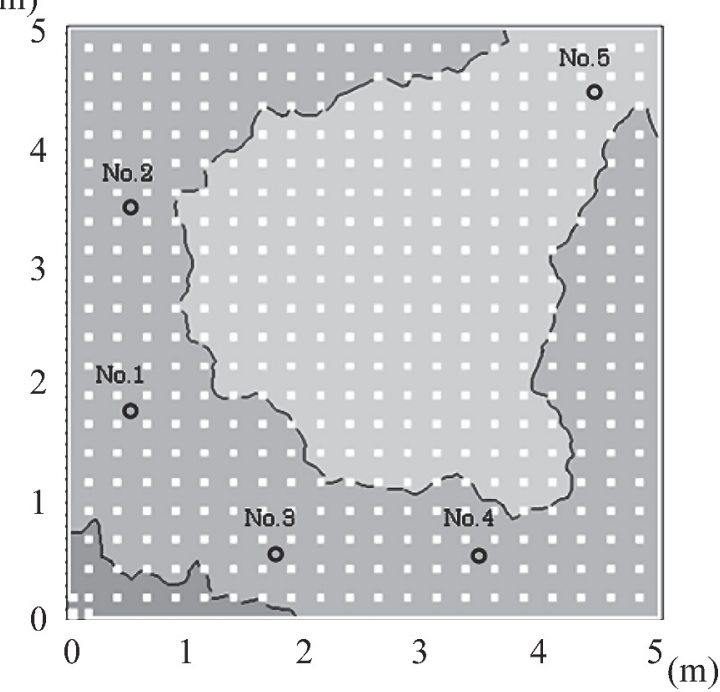

(c) 20 minutes later (m)

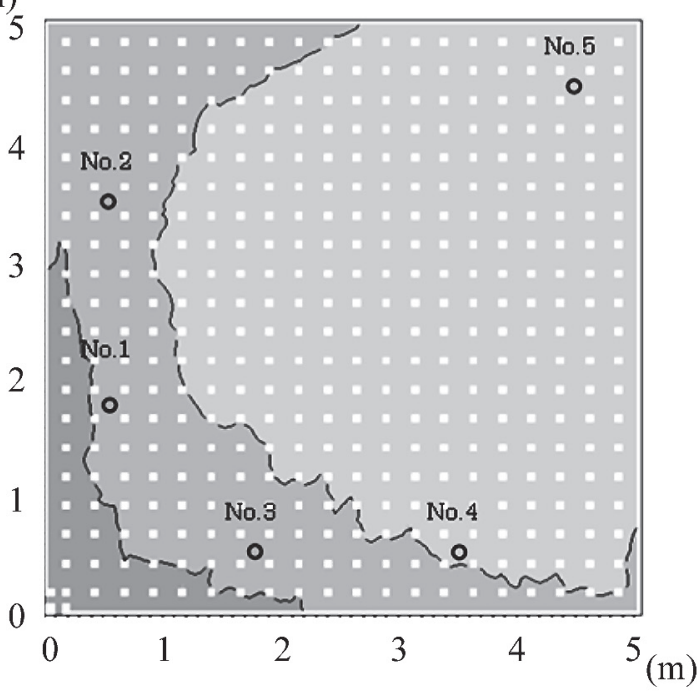

(b) 10 minutes later

(m)

4

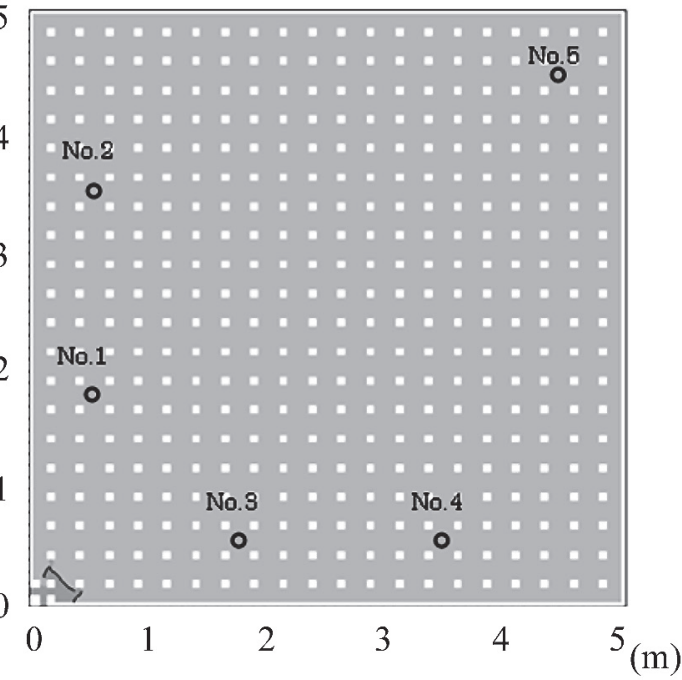

(d) 50 minutes later

Fig. 5. Spatial distribution of T-N with improved scenario.

area in Japan and method of manure design, The research institute of resource circulation in the Japanese Society of Irrigation, Drainage and Rural Engineering, 5: 95-105 (in Japanese with English abstract)

Iwashita, K., Fukushi, K., Sugita, H., Yuge, K., Tanaka, M., \& Nakano, Y. 2008 Establishment of rural resource recycling through the effective application of digested slurry from methane fermentation system to paddy and upland fields, The research institute of resource circulation in the Japanese Society of Irrigation, Drainage and Rural Engineering 4: 55-70 (in Japanese with English abstract)

Lightbody, A. F., Nepf, H. M., \& Bays, J. S. 2009 Modeling the hydraulic effect of transverse deep zones on the performance of short-circuiting constructed treatment wetlands, Ecological Engineering 35: 754-768

Kawanishi, H., Morioka, H., \& Nakata, T. 2007 Optimum System Design for Effective Utilization of Livestock Manure in Rural Area, Journal of the Japan Institute of Energy, 86: 256264 (in Japanese with English abstract)

Ministry of Agriculture, Forestry and Fisheries 2009 Statistics of Agriculture, Forestry and Fisheries. Ministry of Agriculture, Forestry and Fisheries pp.1 http://www.maff. go.jp/j/tokei/kouhyou/sakumotu/menseki/pdf/menseki_ kouti_09.pdf, accessed June 23, 2010 (in Japanese)

Nakamura, S., Sato, G., \& Tanaka, M. 2005 A Study on the Potential of Organic Liquid Fertilizer in Paddy Fields in Order to Support Recycling Society, Environmental study at Nagasaki University, 7: 13-24 (in Japanese with English abstract)

Nakano, A., \& Uehara, Y. 2005 Effects of Organic Fertilization Using Corn Steep Liquor (CSL) and Methane Fermented Cattle Waste (MFC) on aे $^{15} \mathrm{~N}$ Value of Musk Melon (Cucumis melo L.), Bulletin of the National Institute of Vegetable and Tea Science 4: 9-14 (in Japanese with English abstract)

Nakamura, M., Yuyama, Y., Yamamoto, M., Oritate, F., Fujikawa, T., Shimizu, N., Abe, K., \& Aihara, H. 2009 Trouble Records and Analysis of Operation Data for Methane Fermentation Plant, Tech. Rep. Natl. Inst. Rural Eng. Japan, 11-36 (in Japanese with English abstract)

Ryu, C., Sugai, M., Iida, M., Ohdoi K., \& Umeda, M. 2009 Application of Methane Fermentation Digested Sludge to Large Scale Paddy as Fertilizer, The research institute of resource circulation in the Japanese Society of Irrigation, Drainage and Rural Engineering, 5: 77-93 (in Japanese with English abstract) 
Sai, K., Harada, M., Hiramatsu, K., \& Mori, M. 2006 Numerical Study of Water Motion in Lake Koyama using the Twodimensional One-layer Model Incorporated with ADI Method, Sci. Bull. Fac. Agri., Kyushu Univ., 61(2): 281-288 (in Japanese with English summary)

Tanaka, M., Yuge, K., Nanano, Y., \& Iwashita, K. 2009
Investigation of Slurry Irrigation System by Methane Fermentation Digestion for Rice Cultivation, The research institute of resource circulation in the Japanese Society of Irrigation, Drainage and Rural Engineering, 5: 107119 (in Japanese with English abstract) 